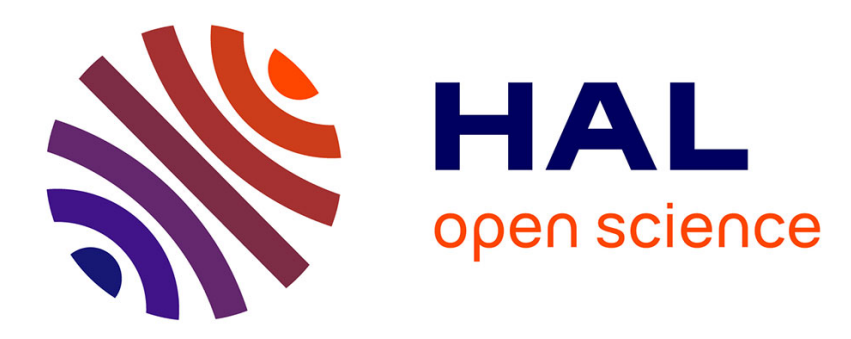

\title{
Current theories of adhesion and their relevance to adhesive technology \\ K. Allen
}

\section{To cite this version:}

K. Allen. Current theories of adhesion and their relevance to adhesive technology. Journal de Physique IV Proceedings, 1993, 03 (C7), pp.C7-1511-C7-1516. 10.1051/jp4:19937236 . jpa-00251873

\section{HAL Id: jpa-00251873 https://hal.science/jpa-00251873}

Submitted on 1 Jan 1993

HAL is a multi-disciplinary open access archive for the deposit and dissemination of scientific research documents, whether they are published or not. The documents may come from teaching and research institutions in France or abroad, or from public or private research centers.
L'archive ouverte pluridisciplinaire $\mathbf{H A L}$, est destinée au dépôt et à la diffusion de documents scientifiques de niveau recherche, publiés ou non, émanant des établissements d'enseignement et de recherche français ou étrangers, des laboratoires publics ou privés. 


\title{
Current theories of adhesion and their relevance to adhesive technology
}

\author{
K.W. ALLEN \\ Ranworth, Tydehams, Newbury RG14 6JT, England
}

Abstract

Contemporary views on the theoretical basis of adhesion applicable to structural adhesive bonding are reviewed; including the significance of mechanical forces, secondary, van der waals interactions and primary chemical bonding.

Each of these is discussed critically and different interpretations are discussed.

Factors necessary for the practical achievement of satisfactory bonding are considered. The significance of the fundamental concepts in relation to practical requirements is considered.

1. Introduction

Although adhesives have been in use for more than three millennia, it is only in quite recent times that there have been any attempts to explain the fundamental processes involved. This in spite of the challenge presented by $s i x$ Isaac Newton, who wrote: (1)

"There are therefore agents in nature able to make the particles of bodies stick together by very strong attractions. And it is the business of experimental philosophy to find them out"

As an aside, it is interesting to note that this suggests a relationship between the origins of cohesion and of adhesion which has only quite recently been developed.

It was not until 1922 that the Adhesives Research Committee of the DSIR made a similar challenging statement (2), which was quickly accepted by McBain who, with his co-workers, made the first steps towards any theory of the fundamentals of adhesion (3) and distinguished between "specific" and "mechanical" adhesion.

since then, there have been a number of attempts to develop a single explanation or theory which would account for all the varied aspects of adhesion. However, it is now clear that several distinct and separate explanations are required to account for various areas of the whole range of phenomena which may be described as adhesion.

This present consideration is confined to those situations which are of major contemporary industrial 
relevance, where adhesive bonds are required to tranamit significant primary stresses - commonly described as "structural adhesives".

\section{Forces available}

Initially, the close similarity must be recognised between the fundamental origins of adhesion - the strength of a bond uniting two different components, often made of two different materials; and cohesion - the strength and integrity of a single material. Ultimately both arise from and depend upon the valence forces of chemistry, there are no others available. The principle characteristics of these forces, and the bonds to which they give rise, are summarised in Table 1. An important feature which must be immediately recognised is the extremely short range over which these forces are effective.

Table 1.

properties of various valence bonds

$\begin{array}{lrll}\text { Bond type } & \begin{array}{c}\text { Equilibrium } \\ \text { length: } \AA\end{array} & \begin{array}{l}\text { Energy: } \\ \text { kJ/mole }\end{array} & \text { Directional? } \\ \begin{array}{l}\text { Primary:- } \\ \text { Ionic }\end{array} & 2-4 & 600-1200 & \text { No } \\ \text { Covalent } & 0.8-3 & 60-800 & \begin{array}{l}\text { Yes } \\ \text { No }\end{array} \\ \begin{array}{l}\text { Metallic } \\ \text { Secondary, van der waals: }\end{array} & 100-350 & \\ \begin{array}{l}\text { Debye induction } \\ \text { Keesom orientation }\end{array} & 2-4 & \sim 20 & \text { Yes } \\ \text { London dispersion } & 4-8 & \sim 40 & \text { No } \\ \text { Hydrogen bonds } & \sim 3 & \sim 60 & \text { Yes }\end{array}$

These are all specific in their action, except the London dispersion forces, which are universal between every pair of particles

When one comes to consider the particular problems of adhesion there are three distinct groups of forces which have generally been seen to be relevant:

1. Mechanical forces

2. Secondary, van der Haals forces (which cause, inter alia, physical adsorption)

3. Primary valence forces (which are responsible for the majority of chemical bonding )

These need to be considered in some detail.

3. Mechanical forces.

Mechanical interlocking is the simplest and oldest explanation of adhesion and has intuitive appeal.

For fibrous materials such as paper, cloth, leather, or wood, it provides an explanation which is demonstrably satisfactory on a relatively macro scale (micron; $10^{-6} \mathrm{~m}$ ) Further, both for the adhesion between the rubber carcase and the reinforcing cords (4) and for the integrity of electroless plated plastics (5) it has been clearly demonstrated that this 
Interlocking is the source of the adhesive strength. Nevertheless some of the experimental results, particularly for timber, appear to indicate that joint strengths decrease with increasing roughness, but if considered very critically to reveal the origin of this discrepancy as being due to damage to the surface in its pretreatment..

For hard, structural materials it is less obviously relevant; - it is difficult to conceive of an adhesive interlocking with the surface of a steel or glass surface. However, it has recently become apparent that it is important for these materials too, but the size of significant topography is much smalier $\left(\AA ; 10^{-10} \mathrm{~m}\right)$.

With techniques for the study of surfaces of ever increasing sophistication; especially through the work of Venables and his co-workers (6) on aluminium and titanium; it has been revealed that the strongest bonds are obtained when the oxide surface of the metal is both porous and has protruding whiskers.

Generally the optimum surface is now understood to be that which has a maximum roughness, provided that the features of that roughness (whiskers, pores, crystallites) are both strong and firmly attached to their substrate, as well as being stable and resistant to hydrolytic degradation.

\section{Secondary, van der haals forces.}

When particles approach sufficiently closely the Secondary, van der wals forces, particularly the London dispersion forces, become effective. These are significant over a distance of up to $10 \AA$. To achieve this intimate approach it is essential that the adhesive wets and spreads across the surface of the, substrate. A very considerable amount of scientific time and energy has been devoted to explorations of the relationships (both thermodynamic and kinetic) of these phenomena involved in the interactions between liguids and solid surfaces. (eg. work by $Z$ isman 7) From this approach, there have been developed wider ideas about the origins of the total adhesive forces (eg work by Good \& Girifalco 8). More recently Fowkes (9) has expounded first the concept that the total adhesion is the result of a summation of contributions from the various types of interaction thus:

$$
\begin{gathered}
W_{A}=w^{d}+w^{*}+w^{i}+w^{a b}+w^{h} \\
\text { where the superscripts indicate: } \\
d-\text { dispersion forces } \\
x-\text { dipole/dipole interactions } \\
i \text { - induced dipole interactions } \\
\text { ab - acid/base interactions } \\
h-\text { hydrogen bonding (although this may more } \\
\text { properly belong as a primary valence } \\
\text { interaction) }
\end{gathered}
$$

He then went on to explore the relative importance of the various contributions. His conclusion was (10) that only electron donor/acceptor interactions are of any significance and that these are most satisfactorily treated using the Lewis acid/base approach. This has yielded significant results, particularly through invoking the thermodynamic methods due 
to Drago (11). However the overall concept has not recelved universal acceptance (12) and cannot be regarded as the final and complete explanation.

If these secondary forces are properly exploited then adhesive bonds of considerable strength result. Although calculations for theoretical values of adhesion are exceedingly difficult, those for cohesion are more straightforward and clearly illustrate how these forces are more than sufficient (by at least an order of magnitude) to provide the observed strengths. This is illustrated in Table 2 .

However, generally these interactions, analogous to physisorption, may be disrupted relatively easily, and particularly under the influence of moisture.

Table 2. Comparison of calculated and observed cohesive strength of materials (13)

All values in
Pa. ( $\left(\mathrm{m}^{-2}\right)$

Phenol/Formaldehyde resin

Cresol/Formaldehyde

resin

Sodium chloride

crystaliine
Calculated

Primary

forces only

$42 \times 10^{9}$

$38 \times 10^{9}$

$3.9 \times 10^{9}$
Observed

Secondary

forces only

$390 \times 10^{6} \quad 76 \times 10^{6}$

$320 \times 10^{6}$

$38 \times 10^{6}$

$196 \times 10^{6}$

$5.9 \times 10^{6}$

5. Primary, chemical bonds

In addition to the secondary interactions which have been considered so far, primary chemical bonds may be formed across an interface between adhesive and substrate. These may provide much greater strength but more important, greater resistance to deterioration under the influence of water. Thus they are more durable. These bonds may be covalent or hydrogen bonds (although these may be regarded by some as secondary interactions)

6. Application to technology

Once one is concerned with the technological exploitation of these forces in the practical use of adhesives, it is essential to remember that there are at least two components to every adhesive joint. First the two adherends which may be both of the same material or may be different; then there is the adhesive itself. All of these can and must be considered and perhaps modified to achieve the optimum result.

It is in this area that the economic considerations become important. A careful analys is must be made of the actual service requirements of a particular bond. This must include: the environment in which it will have to function, the stresses to which it will be subject, whether these will be applied continuously or intermittently and whether impact loading is involved, the cost and penalties of failure. Then, and only then, will it be possible to design for the purpose 
and avold over speciflcation of the various components of the joint.

7. Treatment of adherends (14)

For the most demanding applications, metal adherends

(particularly aluminium and titanium) are usually subjected to a chemical or electro-chemical pre-treatment to provide a surface oxide film of controlled thickness and topography. This preparation may be supplemented by the use of a primer or a coupling agent. strictly a primer is a coating which may reduce the porosity, or modify the surface free energy, or preserve the surface from oxidation etc. between preparation and use. It is often, although not invariably, a diluted solution of the adhesive which is to be used. A coupling agent is quite different. It usually functions by forming primary bonds with the adherend and the adhesive and thus acting as a strong and durable bridge between the two. The most common coupling agents are the siloxane compounds, although others (eg. titanates and zirconium compounds) are also used.

In less critical situations, particularly with ferrous adherends, mechanical abrasion (grit-blasting) is often sufficient to provide an adequate bond.

For non-metallic adherends - glasses, ceramics, organic polymers, composites, less preparation of the surface is often required. Excluding the poly-olefin and fluoro-carbons, removal of adventitious dirt and grease is frequently adequate. With these materials it is necessary to use rigorous methods to change, in a quite fundamental way, the chemical nature of the surface because of the inherently inert nature and the low surface free energy. Satisfactory and durable bonding to glass requires an appropriate coupling agent, almost always a siloxane material.

8. Formulation of Adhesives

The adhesive for any particular application must be formulated with the following considerations:

i. to be able to be applied in an appropriate quantity in the proper place and to remain there until cured, which will involve the rheological properties of a liquid/paste adhesive, or the choice of an adhesive in tape or film form

ii. to cure at a suitable rate under the conditions available in the process, which will depend upon the precise chemistry and catalysts involved as well as the temperature of the process

iii.to achieve adequate cohesive strength in the glue-line to withstand the applied forces

iv. to develop sufficientiy strong bonds to both the adherends.

$v$. to be adequately durable; that is to retain the strength, both in the adhesive bonds and in the glue-line itself, necessary to with stand the service environment

The last two of these requirements will all particularly depend upon proper understanding and utilisation of all the resources which have been consider above. 


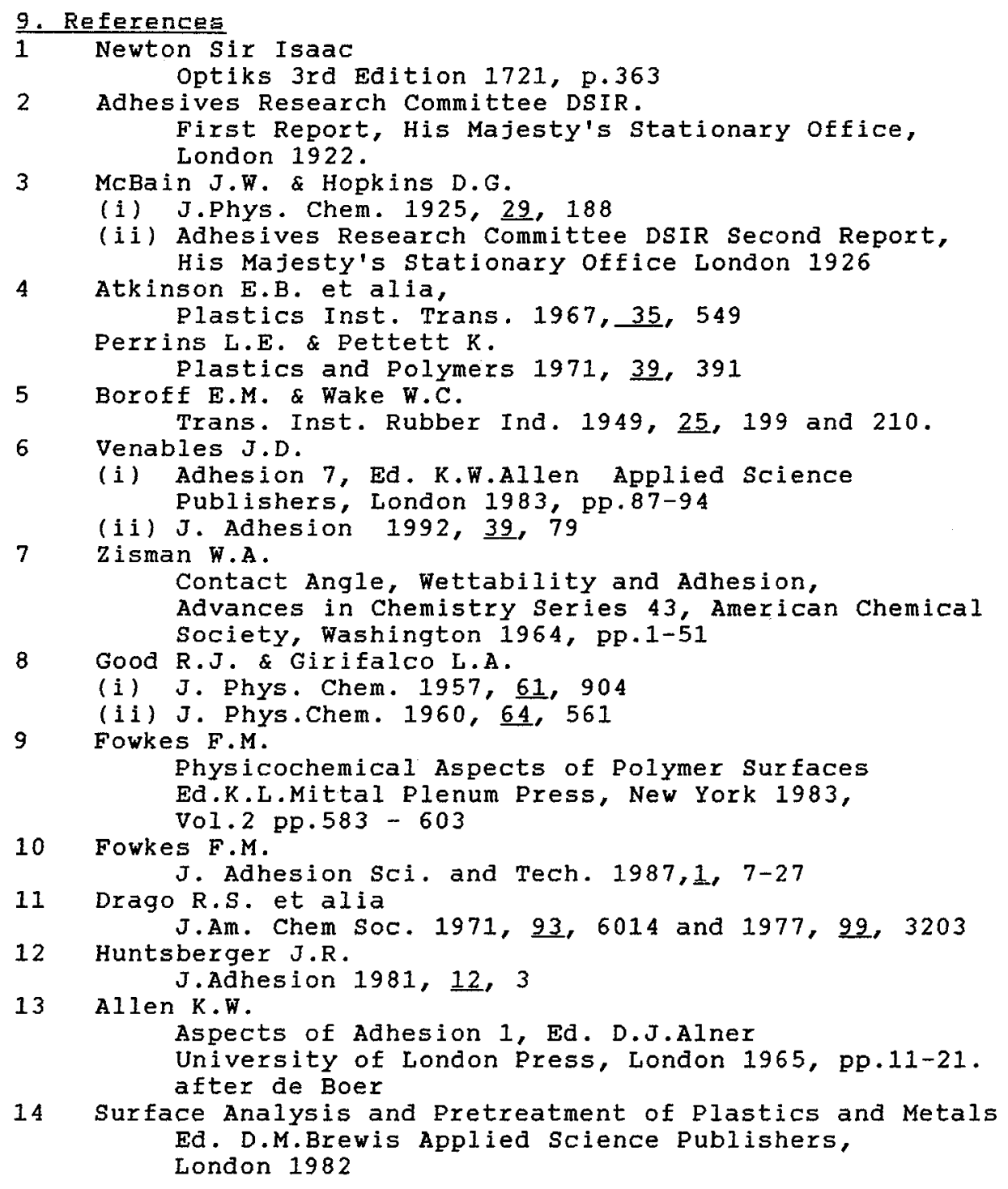

